\title{
Timing of Elective Repeat Cesarean Delivery at Term and Neonatal
}

\section{Outcomes}

Alan T.N. Tita, M.D., Ph.D., Mark B. Landon, M.D., Catherine Y. Spong, M.D., Yinglei Lai, Ph.D., Kenneth J. Leveno, M.D., Michael W. Varner, M.D., Atef H. Moawad, M.D., Steve N. Caritis, M.D., Paul J. Meis, M.D., Ronald J. Wapner, M.D., Yoram Sorokin, M.D., Menachem Miodovnik, M.D., Marshall Carpenter, M.D., Alan M. Peaceman, M.D., Mary J. O'Sullivan, M.D., Baha M. Sibai, M.D., Oded Langer, M.D., John M. Thorp, M.D., Susan M. Ramin, M.D., and Brian M. Mercer, M.D. [on behalf of for the Eunice Kennedy Shriver NICHD Maternal-Fetal Medicine Units Network]

From the University of Alabama at Birmingham, Birmingham (A.T.N.T.); Ohio State University, Columbus (M.B.L.); Eunice Kennedy Shriver National Institute of Child Health and Human Development, Bethesda, MD (C.Y.S.); George Washington University Biostatistics Center, Washington, DC (Y.L.); the University of Texas Southwestern Medical Center, Dallas (K.J.L.); University of Utah, Salt Lake City (M.W.V.); University of Chicago, Chicago (A.H.M.); University of Pittsburgh, Pittsburgh (S.N.C.); Wake Forest University School of Medicine, Winston-Salem, NC (P.J.M.); Thomas Jefferson University, Philadelphia (R.J.W.); Wayne State University, Detroit (Y.S.); University of Cincinnati, Cincinnati, and Columbia University, New York (M.M.); Brown University, Providence, RI (M.C.); Northwestern University, Chicago (A.M.P.); University of Miami, Miami (M.J.O.); University of Tennessee, Memphis (B.M.S.); University of Texas Health Science Center, San Antonio (O.L.); the University of North Carolina, Chapel Hill (J.M.T.); University of Texas Health Science Center, Houston (S.M.R.); and Case Western Reserve University, Cleveland (B.M.M.).

\section{Abstract}

BACKGROUND—Because of increased rates of respiratory complications, elective cesarean delivery is discouraged before 39 weeks of gestation unless there is evidence of fetal lung maturity. We assessed associations between elective cesarean delivery at term (37 weeks of gestation or longer) but before 39 weeks of gestation and neonatal outcomes.

METHODS-We studied a cohort of consecutive patients undergoing repeat cesarean sections performed at 19 centers of the Eunice Kennedy Shriver National Institute of Child Health and Human Development Maternal-Fetal Medicine Units Network from 1999 through 2002. Women with viable singleton pregnancies delivered electively (i.e., before the onset of labor and without any recognized indications for delivery before 39 weeks of gestation) were included. The primary outcome was the composite of neonatal death and any of several adverse events, including respiratory complications, treated hypoglycemia, newborn sepsis, and admission to the neonatal intensive care unit (ICU).

RESULTS-Of 24,077 repeat cesarean deliveries at term, 13,258 were performed electively; of these, $35.8 \%$ were performed before 39 completed weeks of gestation $(6.3 \%$ at 37 weeks and $29.5 \%$

Copyright $\odot 2009$ Massachusetts Medical Society. All rights reserved.

Address reprint requests to Dr. Tita at the Department of Obstetrics and Gynecology, Division of Maternal-Fetal Medicine, University of Alabama at Birmingham, 619 19th St. South, Birmingham, AL 35249, or at alan.tita@obgyn.uab.edu.

*The other members of the Eunice Kennedy Shriver National Institute of Child Health and Human Development (NICHD) Maternal-

Fetal Medicine Units Network are listed in the Appendix.

No potential conflict of interest relevant to this article was reported.

Presented in part at the 28th Annual Meeting of the Society for Maternal-Fetal Medicine, Dallas, January 28-February 2, 2008. 
at 38 weeks) and $49.1 \%$ at 39 weeks of gestation. One neonatal death occurred. As compared with births at 39 weeks, births at 37 weeks and at 38 weeks were associated with an increased risk of the primary outcome (adjusted odds ratio for births at 37 weeks, 2.1 ; 95\% confidence interval [CI], 1.7 to 2.5 ; adjusted odds ratio for births at 38 weeks, $1.5 ; 95 \% \mathrm{CI}, 1.3$ to 1.7 ; $\mathrm{P}$ for trend $<0.001$ ). The rates of adverse respiratory outcomes, mechanical ventilation, newborn sepsis, hypoglycemia, admission to the neonatal ICU, and hospitalization for 5 days or more were increased by a factor of 1.8 to 4.2 for births at 37 weeks and 1.3 to 2.1 for births at 38 weeks.

CONCLUSIONS-Elective repeat cesarean delivery before 39 weeks of gestation is common and is associated with respiratory and other adverse neonatal outcomes.

Infants Born Before 39 Weeks of Gestation are at increased risk for neonatal adverse respiratory outcomes, and the risk increases progressively as gestational age at birth declines.1,2 Thus, prelabor elective delivery (delivery in the absence of a specific maternal or fetal indication) is proscribed before 39 weeks unless fetal lung maturity has been demonstrated. ${ }^{3}, 4$ As compared with infants born vaginally, those born by cesarean section are at increased risk for adverse respiratory outcomes, especially when delivery occurs before the onset of labor. $1,2,5^{-11}$ This increased risk persists even in infants who are delivered by cesarean section at full term (i.e., at or beyond 37 completed weeks of gestation).

The rate of cesarean delivery in the United States rose from $20.7 \%$ in 1996 to $31.1 \%$ in $2006 .{ }^{12}$ A major reason for this increase is the decline in the rate of attempted vaginal birth after cesarean delivery. ${ }^{13}$ Elective cesarean delivery may be scheduled to accommodate patient and physician convenience, and there is a risk that it may be performed earlier than is appropriate. Because approximately $40 \%$ of the 1.3 million cesarean deliveries performed annually in the United States are repeat procedures and the number of cesarean deliveries continues to rise, the timing of elective cesarean delivery has increasingly important public health implications. ${ }^{14,15}$ Therefore, we undertook the present study of a large, prospectively assembled cohort of women in the United States to describe the timing of elective repeat cesarean deliveries and to assess associations between delivery before 39 weeks and the risk of adverse neonatal outcomes.

\section{METHODS \\ PATIENTS}

We selected our study cohort from the cesarean registry of the Eunice Kennedy Shriver National Institute of Child Health and Human Development Maternal-Fetal Medicine Units Network. The registry contains detailed, prospectively collected information on consecutive repeat cesarean deliveries performed at 19 U.S. academic centers from 1999 to $2002 .{ }^{16}$ Women who underwent cesarean delivery were identified daily by dedicated, trained research personnel at each center, who collected maternal and neonatal information on standardized study forms. The data forms allowed for each woman to have one major and one or two secondary indications for the cesarean delivery from an inclusive list of 20 prespecified options that included "other."

Using the listed indications for cesarean delivery (a specific focus of the registry), as well as medical and obstetrical history, we defined a group of women who underwent an elective cesarean delivery (i.e., a delivery performed in the absence of labor or other recognized medical or obstetrical indications for delivery) of a viable infant at 37 weeks of gestation or later (Fig. 1). Women who had multiple gestations or a fetus with a major congenital anomaly were excluded, as were women with other medical or obstetrical conditions that would warrant early or immediate delivery. Deliveries were categorized according to the number of completed weeks of gestation. Gestational age was determined by obstetrical providers with the use of standard criteria that took into consideration the clinical history and the results of the earliest 
ultrasound examination. ${ }^{17}$ If the findings on ultrasound examination were consistent with a gestational age based on a certain date of the last menstrual period, gestational age was determined according to the date of the last menstrual period; if the date of the last menstrual period was uncertain or the findings on ultrasound examination were inconsistent with a gestational age based on the date of the last menstrual period, gestational age was determined according to the results of the ultrasound examination.

\section{STUDY OUTCOMES}

The following neonatal outcomes were studied: death, adverse respiratory outcomes (respiratory distress syndrome or transient tachypnea of the newborn), hypoglycemia, newborn sepsis, confirmed seizures, necrotizing enterocolitis, hypoxic-ischemic encephalopathy, cardiopulmonary resuscitation or ventilator support within 24 hours after birth, umbilical-cordblood arterial pH below 7.0, a 5-minute Apgar score of 3 or below, admission to the neonatal intensive care unit (ICU), and prolonged hospitalization (5 days or longer). The prespecified primary outcome was a composite that included any of the above outcomes. The infants were followed up until discharge from the hospital or 120 days after birth, whichever came first. ${ }^{16}$

The diagnosis of respiratory distress syndrome required signs of respiratory distress, consistent radiologic features, and oxygen therapy with a fraction of inspired oxygen $\left(\mathrm{FiO}_{2}\right)$ of 0.40 or greater for at least 24 hours or until death. Transient tachypnea of the newborn was defined by the presence of tachypnea within hours after birth and typical radiologic findings. The diagnosis of necrotizing enterocolitis required confirmation by radiologic findings, surgery, or autopsy. The diagnosis of hypoglycemia required a serum or plasma glucose level of less than $35 \mathrm{mg}$ per deciliter (1.9 mmol per liter) and treatment with intravenous glucose. Newborn sepsis included both suspected infections (with clinical findings suggesting infection) and proved infections (as confirmed in a subgroup of neonates with positive cultures of blood, cerebrospinal fluid, or urine obtained by catheterization or suprapubic aspiration; cardiovascular collapse; or an unequivocal radiograph confirming infection in a neonate with clinical sepsis). Small for gestational age was defined as a birth weight less than or equal to the 10th percentile, and large for gestational age as a birth weight greater than or equal to the 90th percentile derived from sex- and race-specific growth curves. ${ }^{18}$

\section{STATISTICAL ANALYSIS}

Data were analyzed with the use of SAS software, version 8.2. The incidence of adverse neonatal outcomes was calculated for each completed week of gestation at the time of cesarean delivery. The Cochran-Armitage test for trend was used to assess trends in the incidence rates of outcomes. Adjusted odds ratios for the association between neonatal outcomes and gestational age at delivery relative to 39 completed weeks of gestation were derived from logistic-regression models that included maternal age, self-reported race or ethnic group, marital status, the number of previous cesarean deliveries, payor, the presence or absence of smoking during pregnancy, and the presence or absence of diet-controlled gestational diabetes. The attributable risk of the primary outcome was calculated with the use of the following formula: $100 \times($ relative risk -1$) \div$ relative risk, where relative risk is the risk at 37 or 38 weeks divided by the risk at 39 weeks. ${ }^{19} \mathrm{~A}$ nominal two-sided $\mathrm{P}$ value of less than 0.05 was considered to indicate statistical significance; no adjustments were made for multiple comparisons.

The study was approved by the institutional review boards of each clinical center and the datacoordinating center. The data were transmitted to the coordinating center without patient identification. Informed consent was not required. The staff of the George Washington University Biostatistics Center had complete access to the data and performed the analyses. 


\section{RESULTS}

\section{PATIENTS}

A total of 28,867 women who delivered by repeat cesarean section were enrolled in the registry; 24,077 of the cesarean deliveries were performed at term. After the exclusion of women who had multiple gestations, a fetus with a major congenital anomaly or indications for immediate or early delivery, we identified 13,258 women who underwent an elective cesarean section at term (Fig. 1). The week of gestation at delivery was confirmed by a first- or second-trimester ultrasound examination in $76.8 \%$ of pregnancies.

Among the women who underwent elective repeat cesarean section at term, $6.3 \%$ underwent the procedure at 37 completed weeks of gestation, $29.5 \%$ at 38 weeks, $49.1 \%$ at 39 weeks, and just over $15 \%$ at 40 weeks or later (Fig. 2). Thus, 35.8\% (95\% confidence interval [CI], 35.0 to 36.6) of elective repeat cesarean deliveries were performed before 39 weeks of gestation. The median proportion of deliveries performed before 39 weeks of gestation among the 19 centers was $36.5 \%$, and the range was 18.6 to $52.5 \%$.

Maternal and infant characteristics varied according to the number of completed weeks of gestation at delivery (Table 1). As compared with women who delivered at 39 weeks or later, women who delivered before 39 weeks of gestation tended to be older and to have a lower body-mass index at the time of delivery. They were also significantly more likely to be white, to have private insurance, to be married, and to have had a first- or second-trimester ultrasound examination for dating the pregnancy. The mean birth weight of the infants and the prevalence of large-for-gestational-age infants increased with higher gestational age at delivery.

\section{STUDY OUTCOMES}

There was only one neonatal death, which occurred in an infant born at 39 weeks. Five neonates had seizures, and none had hypoxic-ischemic encephalopathy or necrotizing enterocolitis. The rate of the primary outcome of any neonatal adverse outcome or death varied according to center, with a median of $10.5 \%$ (interquartile range, 7.0 to 11.7). Table 2 shows the incidence rates of neonatal outcomes according to gestational age at birth. The primary outcome was significantly less likely as gestational age at birth increased from 37 to 39 weeks (with rates of $15.3 \%$ at 37 weeks and $8.0 \%$ at 39 weeks; P for trend $<0.001$ ). Similar trends of decreasing incidence with greater gestational age were also noted for any adverse respiratory outcome and its components (transient tachypnea of the newborn or respiratory distress syndrome), admission to the neonatal ICU, need for cardiopulmonary resuscitation or mechanical ventilation within 24 hours after delivery, newborn sepsis, hypoglycemia, and prolonged hospitalization. Three of the four neonates who had cardiopulmonary resuscitation also required mechanical ventilation.

We also assessed the outcomes for deliveries performed beyond 39 completed weeks of gestation. The incidence rates of each neonatal outcome for infants born at 40 weeks were similar to those for infants born at 39 weeks. However, there were significant trends toward an increased incidence of the primary outcome for delivery at more than 40 weeks of gestation ( $P$ for trend $<0.001)$. Similar trends were noted for respiratory complications $(P=0.002)$, admission to the neonatal ICU $(\mathrm{P}<0.001)$, newborn sepsis $(\mathrm{P}<0.001)$, and prolonged hospitalization $(\mathrm{P}<0.001)$; the findings for other outcomes were limited by small numbers. Figure 2 shows the overall relationship between gestational age at delivery and the primary outcome.

The trends toward the decreasing incidence of the primary outcome and of individual neonatal complications with increasing gestational age at term birth up to 39 weeks of gestation remained significant in analyses adjusted for potential confounders; the adjusted odds ratios ranged from 
1.8 to 4.2 at 37 weeks of gestation and from 1.3 to 2.1 at 38 weeks of gestation, as compared with 1.0 at 39 weeks of gestation (Table 3). Delivery at 40 weeks was not associated with significantly increased morbidity as compared with delivery at 39 weeks, but delivery at 41 weeks or at 42 weeks or more was associated with increases in several complications similar in magnitude to those observed for births at 38 weeks and 37 weeks, respectively. Other variables associated with the primary outcome in multivariate analyses were race or ethnic group, number of previous cesarean deliveries, payor, presence or absence of diet-controlled gestational diabetes mellitus, and maternal age (see the Supplementary Appendix, available with the full text of this article at NEJM.org).

Adjusted analyses of the primary outcome restricted to births for which the gestational age was estimated by a first- or second-trimester ultrasound examination yielded similar results. Furthermore, the exclusion of the $1 \%$ of infants weighing less than $2500 \mathrm{~g}$ at birth did not change the prevalence of delivery before 39 weeks or materially affect the association between earlier gestational age at delivery and the primary outcome. Analyses adjusted for study center gave similar results. Furthermore, when the analysis of deliveries before 39 weeks was restricted to the $51.9 \%$ of deliveries ( 2463 of 4743 ) that occurred during the last 3 days before week 39 (i.e., from 38 weeks 4 days to 38 weeks 6 days), the risk of the primary outcome remained higher than that for deliveries at 39 completed weeks (relative risk, 1.21; 95\% CI, 1.04 to $1.40 ; \mathrm{P}=0.01)$.

The attributable risk of the primary outcome due to elective delivery before 39 weeks of gestation was $48 \%$ at 37 weeks (a result implying that postponing elective delivery to 39 weeks might prevent $48 \%$ of cases of the primary outcome among deliveries at 37 weeks of gestation) and $27 \%$ at 38 weeks of gestation.

\section{DISCUSSION}

In this large, multicenter study in the United States, more than one third of elective repeat cesarean deliveries at term were performed before 39 weeks of gestation. As compared with deliveries at 39 weeks, these early deliveries were associated with a significantly increased risk of a composite outcome that included neonatal death or any adverse outcome, as well as increased risks of individual neonatal adverse outcomes that included respiratory complications and admission to the neonatal ICU. The risks of individual adverse neonatal outcomes were higher for delivery at 37 weeks (by a factor of 1.8 to 4.2 ) than for delivery at 38 weeks (by a factor of 1.3 to 2.1) relative to delivery at 39 weeks of gestation. Delaying delivery beyond 40 weeks was also associated with increased rates of neonatal adverse outcomes. However, only one neonatal death and no cases of hypoxic-ischemic encephalopathy or necrotizing enterocolitis were observed in this select cohort of low-risk term births.

The validity of these findings depends on our ability to have correctly identified and excluded deliveries for which there were indications for delivery before 39 weeks. Specifically trained and certified personnel scrutinized the charts of all women in the registry and their infants for indications for cesarean delivery. Our criteria for elective cesarean delivery were stringent. Although fetal growth restriction was not captured as a specific indication for cesarean delivery, our results remained unchanged after the exclusion of potentially growth-restricted neonates (birth weight $<2500 \mathrm{~g}$ ). It is possible that some earlier term deliveries may have been performed because of maternal perception of reduced fetal movement (a sign of potential fetal compromise). Although such patients should generally undergo antepartum fetal testing for signs suggesting fetal compromise ${ }^{20}$ (which would be coded as an indication for delivery), clinicians may forgo fetal testing before delivery at term. This might have affected our results in the unlikely event that more of such deliveries occurred before than after 39 weeks. 
Also important is the accuracy with which we assigned gestational age. Our results were materially unchanged in analyses restricted to infants with gestational age estimated by firstor second-trimester ultrasound examination, rather than by third-trimester ultrasound examination or last menstrual period alone. The increase in mean birth weight as the assigned gestational age advanced provides further support for the accuracy of our dating.

Some limitations of the study should be noted. Deliveries that occurred before 39 weeks of gestation but after positive results of tests of lung maturity would not be considered inappropriately early ${ }^{3,4}$; however, we did not have information about testing for lung maturity. One retrospective study of cesarean delivery at a single U.S. center, although potentially nonrepresentative of the general population, showed that $22 \%$ of elective cesarean deliveries were performed early without any tests for fetal lung maturity. ${ }^{21}$ Further study is warranted to assess whether an increased rate of adverse outcomes in deliveries occurring before 39 weeks is explained entirely by failure to test for fetal lung maturity before delivery, or whether testing indicating "maturity" does not fully protect against an increased rate of adverse outcomes in these early births.

Our study design did not allow us to assess whether there was an increase in stillbirths that was associated with delaying delivery until at least 39 weeks. The risk of unexplained stillbirth has been reported to be no greater than 0.2 of 1000 births at 37 weeks and 0.5 of 1000 births at 38 weeks among Scottish and Canadian cohorts of women who had previous cesarean deliveries. 22,23 On the assumption of a higher average risk in our U.S. population of approximately 0.5 of 1000 births per week, we estimate that two or three stillbirths might have been averted in our cohort by delivery before 39 weeks. However, as compared with delivery at 39 weeks, earlier delivery increased the rate of adverse neonatal outcomes in the cohort, including 176 extra cases of the primary outcome, 145 admissions to the neonatal ICU, and 63 cases of respiratory distress syndrome. Although there were no neonatal deaths associated with early delivery in our cohort, the sample size was too small to evaluate an increase in this rare outcome, since more than 20,000 subjects would be needed to measure an incidence of 0.1 to $1.0 \%$ with adequate confidence and precision.

Since the vast majority of women with a previous cesarean delivery elect a repeat cesarean delivery, ${ }^{13,14}$ since more than $25 \%$ of primary cesarean deliveries are performed before the onset of labor, ${ }^{24}$ and since there may be increasing enthusiasm for cesarean delivery on maternal request, ${ }^{25}$ the timing of cesarean delivery and its effect on infant outcomes have substantial public health importance. We identified a recent systematic review ${ }^{26}$ and five individual European studies $1,2,27^{-29}$ that examined the association of the timing of elective cesarean delivery with neonatal outcomes. The rates of elective cesarean delivery before 39 weeks were higher in the European cohorts (ranging from 51 to 83\%) than in our study. Because these studies vary considerably in their definitions of "elective" and in their criteria for inclusion and exclusion, their results cannot be directly compared with ours. Even so, the studies consistently demonstrated increased respiratory morbidity with elective cesarean delivery before 39 weeks. These studies focused primarily on respiratory complications, and the combined number of women undergoing elective cesarean deliveries was only about half that of our study.

The composite primary outcome occurred in approximately $10 \%$ of all neonates in our study. Although the majority of deliveries before 39 weeks occurred at 38 weeks 4 days through 38 weeks 6 days, deliveries occurring during this period were also associated with increased neonatal morbidity. We also observed a higher risk of neonatal complications with cesarean delivery at 41 weeks or later, although the overall proportion of mothers delivering this late was small $(<5 \%)$. These findings suggest that in addition to the risk of stillbirth, which is almost doubled at 41 weeks of gestation and increased by a factor of up to five at 42 or more weeks 
as compared with 39 weeks, ${ }^{22,} 23$ the risk of neonatal complications may also be increased by delaying elective cesarean delivery beyond 39 or 40 completed weeks of gestation.

Our combined study population reflects the socioeconomic and demographic spectrum of the United States. ${ }^{30}$ Although we studied only repeat procedures, which constitute the majority of elective cesarean deliveries, previous studies that included primary cesarean deliveries have shown similar increases in respiratory complications with delivery before 39 weeks of gestation. ${ }^{28,29}$

Our results indicate that a high proportion of elective cesarean deliveries in the United States are performed before 39 weeks. This may be driven by several factors, including a woman's desire to give birth once term is attained and an obstetrician's desire to schedule the procedure at a convenient time. ${ }^{25}$ These early deliveries are associated with a preventable increase in neonatal morbidity and admissions to the neonatal ICU, which carry a high economic cost. These findings support recommendations to delay elective delivery until 39 weeks of gestation and should be helpful in counseling.

\section{Acknowledgments}

Supported by grants (HD21410, HD21414, HD27860, HD27861, HD27869, HD27905, HD27915, HD27917, HD34116, HD34122, HD34136, HD34208, HD34210, HD40500, HD40485, HD40544, HD40545, HD40560, HD40512, HD36801) from the National Institute of Child Health and Human Development (NICHD). Dr. Tita is supported by NICHD grant HD001258 as a Women's Reproductive Health Research Scholar.

We thank Dwight J. Rouse, M.D., M.S.P.H., for contributing to the development of this study concept and critically reviewing earlier drafts of the manuscript; Dr. Steven G. Gabbe, Vanderbilt University, Nashville, chair of the Maternal-Fetal Medicine Units Network Steering Committee for the study; and the following core committee members: Francee Johnson, B.S.N., Ohio State University, and Julia McCampbell, R.N., University of Texas Southwestern Medical Center, for primary protocol development and coordination between clinical research centers; Elizabeth Thom, Ph.D., and Sharon Gilbert, M.S., M.B.A., George Washington University Biostatistics Center, for protocol and data management and statistical analysis; and John C. Hauth, M.D., University of Alabama at Birmingham, for protocol development and oversight.

\section{APPENDIX}

In addition to the authors, the members of the Eunice Kennedy Shriver National Institute of Child Health and Human Development (NICHD) Maternal-Fetal Medicine Units Network are as follows: Ohio State University — J. Iams, F. Johnson, S. Meadows, H. Walker; University of Alabama at Birmingham - D. Rouse, J. Hauth, A. Northen, S. Tate; University of Texas Southwestern Medical Center - S. Bloom, J. McCampbell, D. Bradford; University of Utah - M. Belfort, F. Porter, B. Oshiro, K. Anderson, A. Guzman; University of Chicago - J. Hibbard, P. Jones, M. Ramos-Brinson, M. Moran, D. Scott; University of Pittsburgh - K. Lain, M. Cotroneo, D. Fischer, M. Luce; Wake Forest University - M. Harper, M. Swain, C. Moorefield, K. Lanier, L. Steele; Thomas Jefferson University - A. Sciscione, M. DiVito, M. Talucci, M. Pollock; Wayne State University - M. Dombrowski, G. Norman, A. Millinder, C. Sudz, B. Steffy; University of Cincinnati - T. Siddiqi, H. How, N. Elder; Columbia University - F. Malone, M. D'Alton, V. Pemberton, V. Carmona, H. Husami; Brown University - H. Silver, J. Tillinghast, D. Catlow, D. Allard; Northwestern University - M. Socol, D. Gradishar, G. Mallett; University of Miami - G. Burkett, J. Gilles, J. Potter, F. Doyle, S. Chandler; University of Tennessee - W. Mabie, R. Ramsey; University of Texas at San Antonio - O. Langer, S. Barker, M. Rodriguez; University of North Carolina - K. Moise, K. Dorman, S. Brody, J. Mitchell; University of Texas at Houston - L. Gilstrap, M. Day, M. Kerr, E. Gildersleeve; Case Western Reserve University - P. Catalano, C. Milluzzi, B. Slivers, C. Santori; George Washington University Biostatistics Center - E. Thom, S. Gilbert, H. Juliussen-Stevenson, M. Fischer; Eunice Kennedy Shriver NICHD — D. McNellis, K. Howell, S. Pagliaro. 


\section{REFERENCES}

1. Morrison JJ, Rennie JM, Milton PJ. Neonatal respiratory morbidity and mode of delivery at term: influence of timing of elective caesarean section. Br J Obstet Gynaecol 1995;102:101-106. [PubMed: 7756199]

2. Zanardo V, Simbi AK, Franzoi M, Soldà G, Salvadori A, Trevisanuto D. Neonatal respiratory morbidity risk and mode of delivery at term: influence of timing of elective caesarean delivery. Acta Paediatr 2004;93:643-647. [PubMed: 15174788]

3. Fetal maturity assessment prior to elective repeat cesarean delivery: ACOG Committee Opinion: Committee on Obstetrics: Maternal and Fetal Medicine. No. 98 - September 1991 (replaces no. 77, January 1990). Int J Gynaecol Obstet 1992;38:327. [PubMed: 1358695]

4. American College of Obstetricians and Gynecologists. ACOG Committee Opinion no. 394, December 2007: cesarean delivery on maternal request. Obstet Gynecol 2007;110:1501-1504. [PubMed: 18055756]

5. Richardson BS, Czikk MJ, daSilva O, Natale R. The impact of labor at term on measures of neonatal outcome. Am J Obstet Gynecol 2005;192:219-226. [PubMed: 15672028]

6. Levine EM, Ghai V, Barton JJ, Strom CM. Mode of delivery and risk of respiratory diseases in newborns. Obstet Gynecol 2001;97:439-442. [PubMed: 11239653]

7. Hook B, Kiwi R, Amini SB, Fanaroff A, Hack M. Neonatal morbidity after elective repeat cesarean section and trial of labor. Pediatrics 1997;100:348-353. [PubMed: 9282704]

8. Annibale DJ, Hulsey TC, Wagner CL, Southgate WM. Comparative neonatal morbidity of abdominal and vaginal deliveries after uncomplicated pregnancies. Arch Pediatr Adolesc Med 1995;149:862867. [PubMed: 7633538]

9. Hales KA, Morgan MA, Thurnau GR. Influence of labor and route of delivery on the frequency of respiratory morbidity in term neonates. Int J Gynaecol Obstet 1993;43:35-40. [PubMed: 7904952]

10. Cohen M, Carson BS. Respiratory morbidity benefit of awaiting onset of labor after elective cesarean section. Obstet Gynecol 1985;65:818-824. [PubMed: 4000571]

11. Bowers SK, MacDonald HM, Shapiro ED. Prevention of iatrogenic neonatal respiratory distress syndrome: elective repeat cesarean section and spontaneous labor. Am J Obstet Gynecol 1982;143:186-189. [PubMed: 7081331]

12. Hamilton BE, Martin JA, Ventura SJ. Births: preliminary data for 2006. Natl Vital Stat Rep 2007;56 (7):1-18. [PubMed: 18277471]

13. Gregory KD, Curtin SC, Taffel SM, Notzon FC. Changes in indications for cesarean delivery: United States, 1985 and 1994. Am J Public Health 1998;88:1384-1387. [PubMed: 9736883]

14. Menacker F. Trends in cesarean rates for first births and repeat cesarean rates for low-risk women: United States, 1990-2003. Natl Vital Stat Rep 2005;54(4):1-8.

15. Menacker F, Declercq E, Macdorman MF. Cesarean delivery: background, trends, and epidemiology. Semin Perinatol 2006;30:235-241. [PubMed: 17011392]

16. Landon MB, Hauth JC, Leveno KJ, et al. Maternal and perinatal outcomes associated with a trial of labor after prior cesarean delivery. N Engl J Med 2004;351:2581-2589. [PubMed: 15598960]

17. American Academy of Pediatrics, American College of Obstetricians and Gynecologists. Guidelines for perinatal care. 6th ed.. Elk Grove Village, IL: American Academy of Pediatrics; 2007.

18. Alexander GR, Kogan MD, Himes JH. 1994-1996 U.S. singleton birth weight percentiles for gestational age by race, Hispanic origin, and gender. Matern Child Health J 1999;3:225-231. [PubMed: 10791363]

19. Szklo, M.; Nieto, FJ. Epidemiology: beyond the basics. Gaithersburg, MD: Aspen; 2000.

20. ACOG practice bulletin: antepartum fetal surveillance. No. 9, October 1999 (replaces Technical Bulletin no. 188, January 1994): clinical management guidelines for obstetrician-gynecologists. Int J Gynaecol Obstet 2000;68:175-185. [PubMed: 10717828]

21. Laye MR, Dellinger EH. Timing of scheduled cesarean delivery in patients on a teaching versus private service: adherence to American College of Obstetricians and Gynecologists guidelines and neonatal outcomes. Am J Obstet Gynecol 2006;195:577-584. [PubMed: 16777051]

22. Smith GC, Pell JP, Dobbie R. Caesarean section and risk of unexplained stillbirth in subsequent pregnancy. Lancet 2003;362:1779-1784. [PubMed: 14654315] 
23. Wood SL, Chen S, Ross S, Sauve R. The risk of unexplained antepartum stillbirth in second pregnancies following caesarean section in the first pregnancy. BJOG 2008;115:726-731. [PubMed: 18410656]

24. Meikle SF, Steiner CA, Zhang J, Lawrence WL. A national estimate of the elective primary cesarean delivery rate. Obstet Gynecol 2005;105:751-756. [PubMed: 15802401]

25. National Institutes of Health state-of-the-science conference statement: cesarean delivery on maternal request March 27-29, 2006. Obstet Gynecol 2006;107:1386-1397. [PubMed: 16738168]

26. Hansen AK, Wisborg K, Uldbjerg N, Henriksen TB. Elective caesarean section and respiratory morbidity in the term and near-term neonate. Acta Obstet Gynecol Scand 2007;86:389-394. [PubMed: 17486457]

27. Graziosi GC, Bakker CM, Brouwers HA, Bruinse HW. Elective cesarean section is preferred after the completion of a minimum of 38 weeks of pregnancy. Ned Tijdschr Geneeskd 1998;142:2300 2303. [PubMed: 9864525]

28. van den Berg A, van Elburg RM, van Geijn HP, Fetter WP. Neonatal respiratory morbidity following elective caesarean section in term infants: a 5-year retrospective study and a review of the literature. Eur J Obstet Gynecol Reprod Biol 2001;98:9-13. [PubMed: 11516792]

29. Hansen AK, Wisborg K, Uldbjerg N, Henriksen TB. Risk of respiratory morbidity in term infants delivered by elective caesarean section: cohort study. BMJ 2008;336:85-87. [PubMed: 18077440]

30. Martin JA, Hamilton BE, Sutton PD, Ventura SJ, Menacker F, Munson ML. Births: final data for 2002. Natl Vital Stat Rep 2003;52(10):1-113. [PubMed: 14717305] 


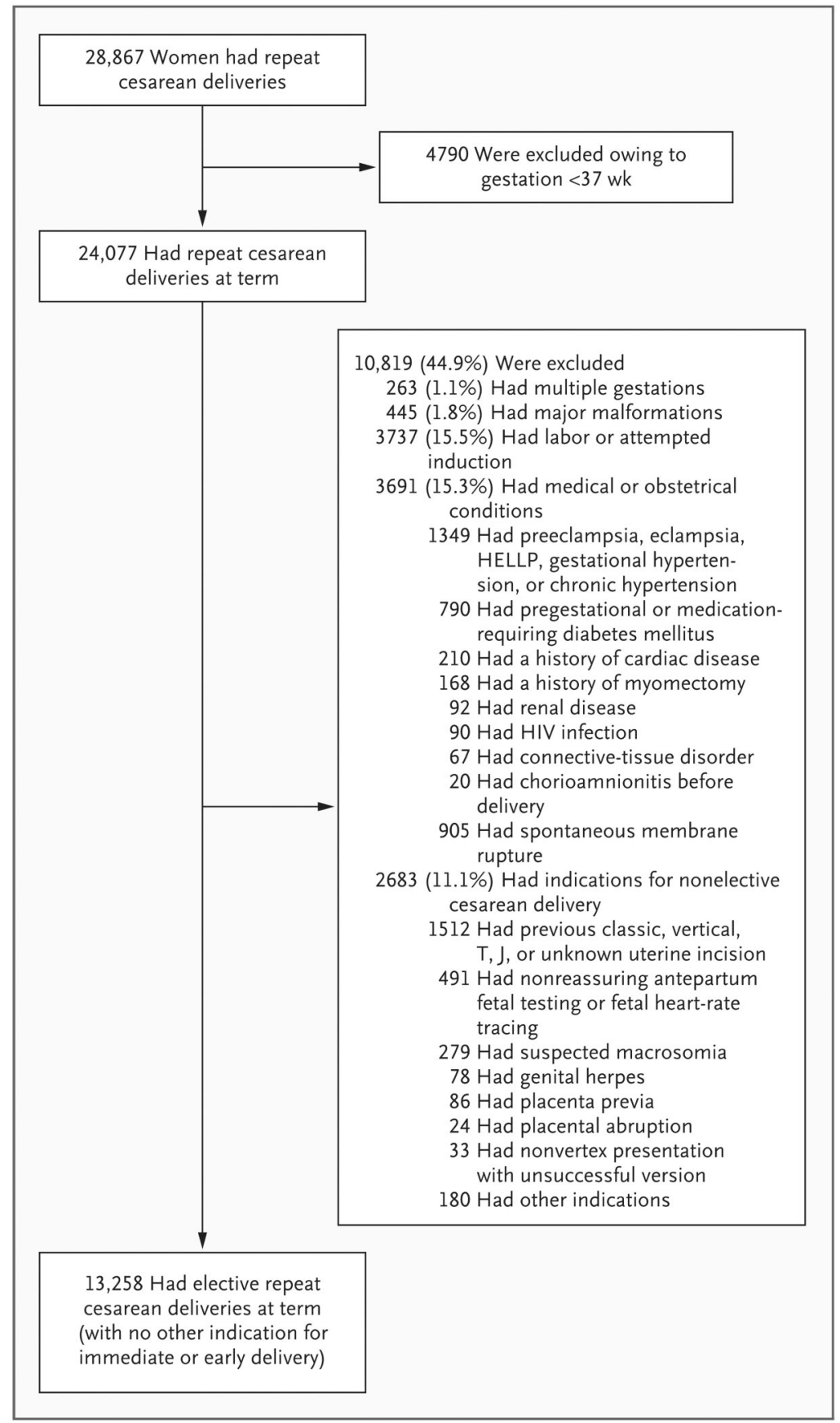

Figure 1.

Flow Chart Detailing Exclusion Criteria Applied to Identify Elective Cesarean Sections. HELLP denotes hemolysis, elevated liver-enzyme levels, and low platelet count, and HIV human immunodeficiency virus. 


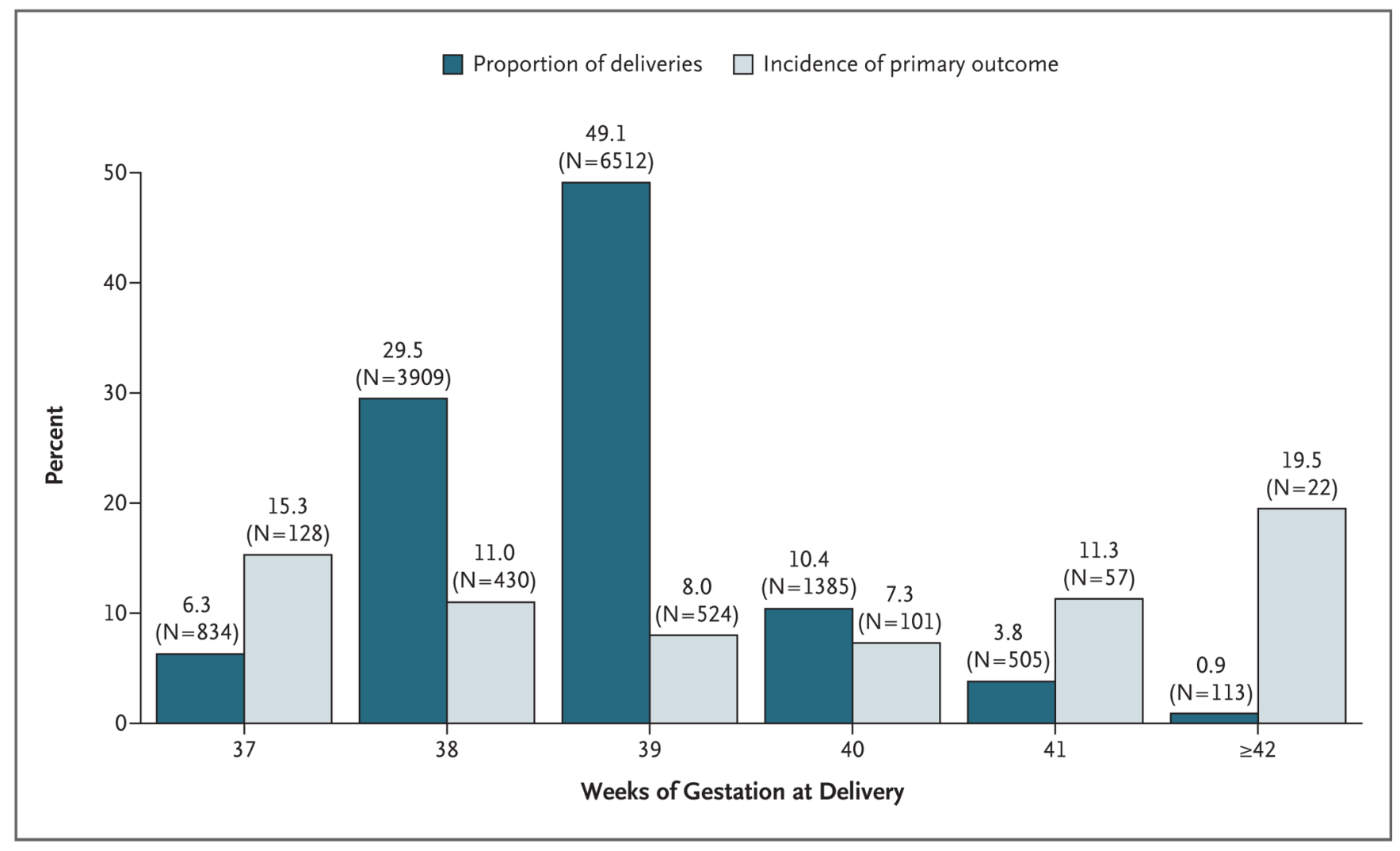

Figure 2.

Timing of Elective Repeat Cesarean Delivery and the Incidence of the Primary Outcome According to the Number of Completed Weeks of Gestation. 


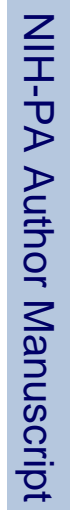

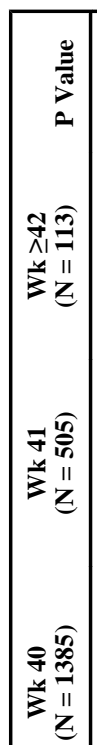

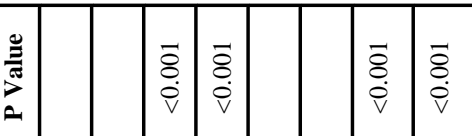

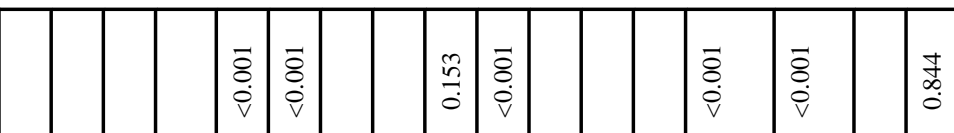

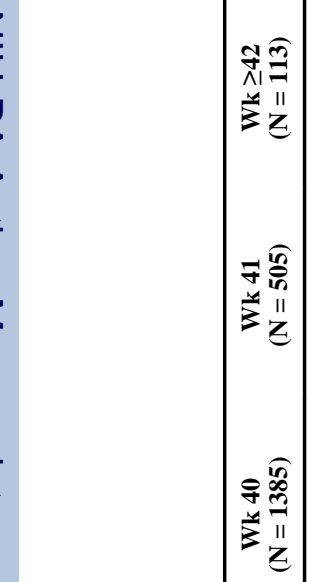

(

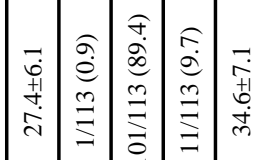

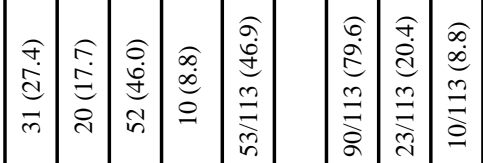

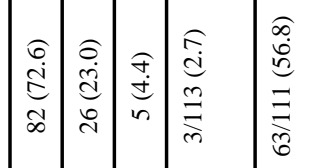

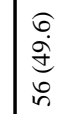

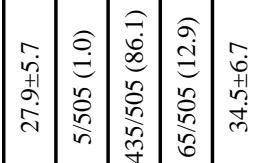

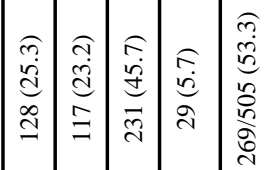

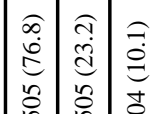

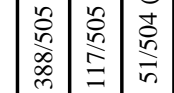

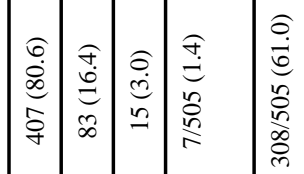

负

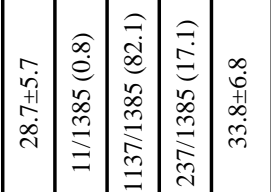

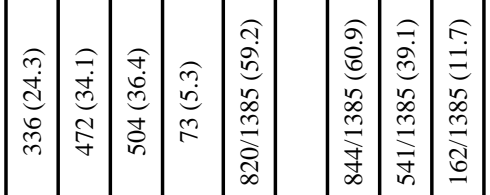

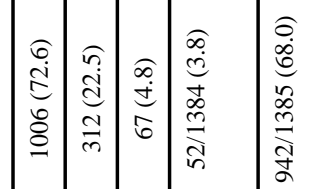

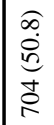

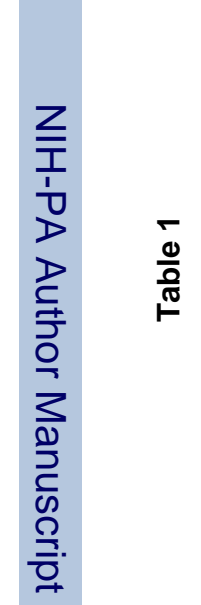

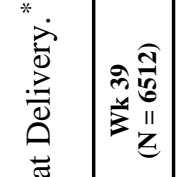

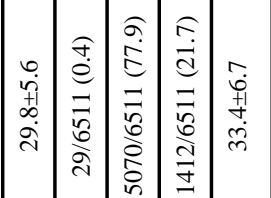

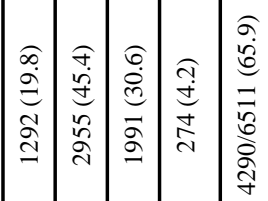

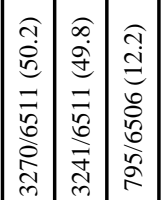

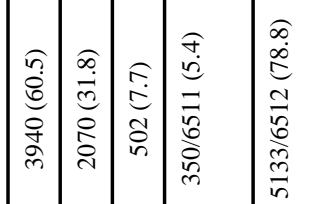

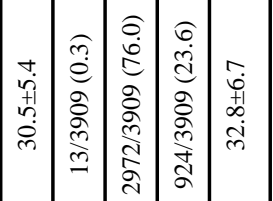

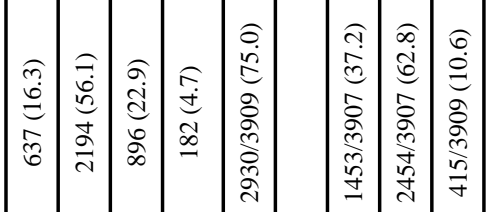

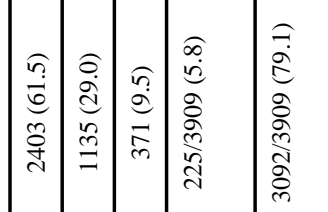

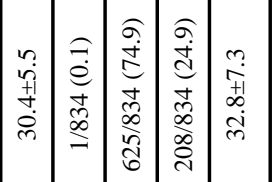

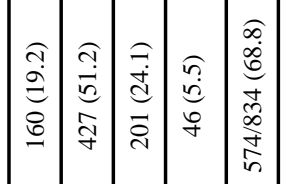

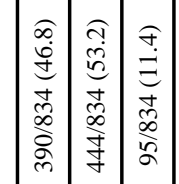

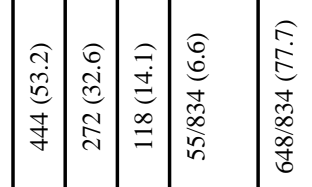

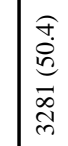

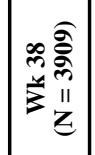

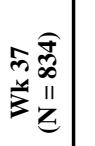

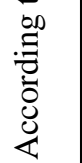

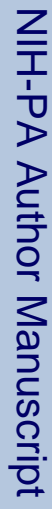

竞

(1)

|

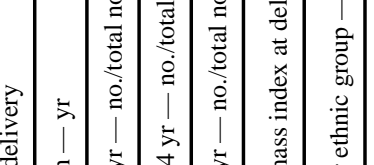

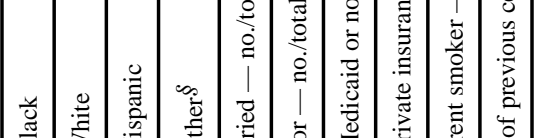

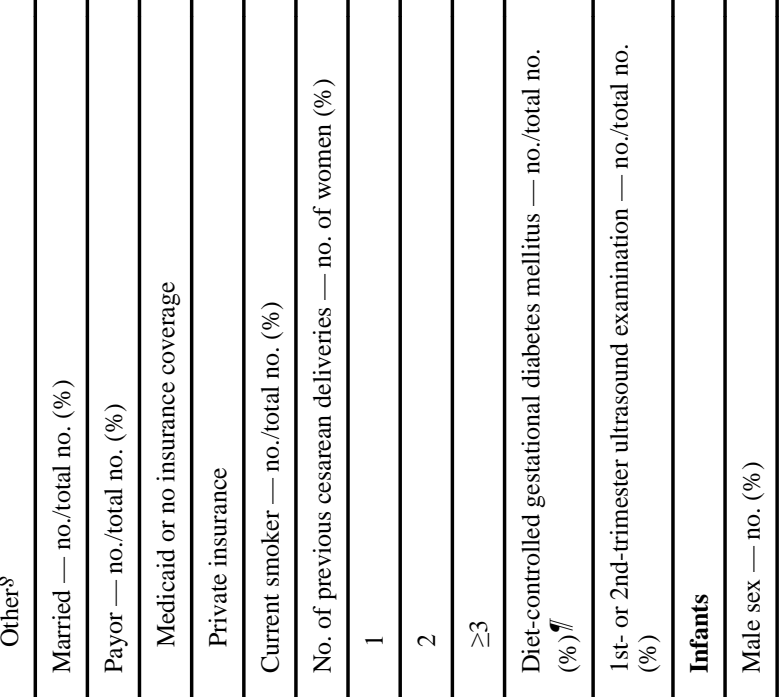

N Engl J Med. Author manuscript; available in PMC 2010 January 26. 


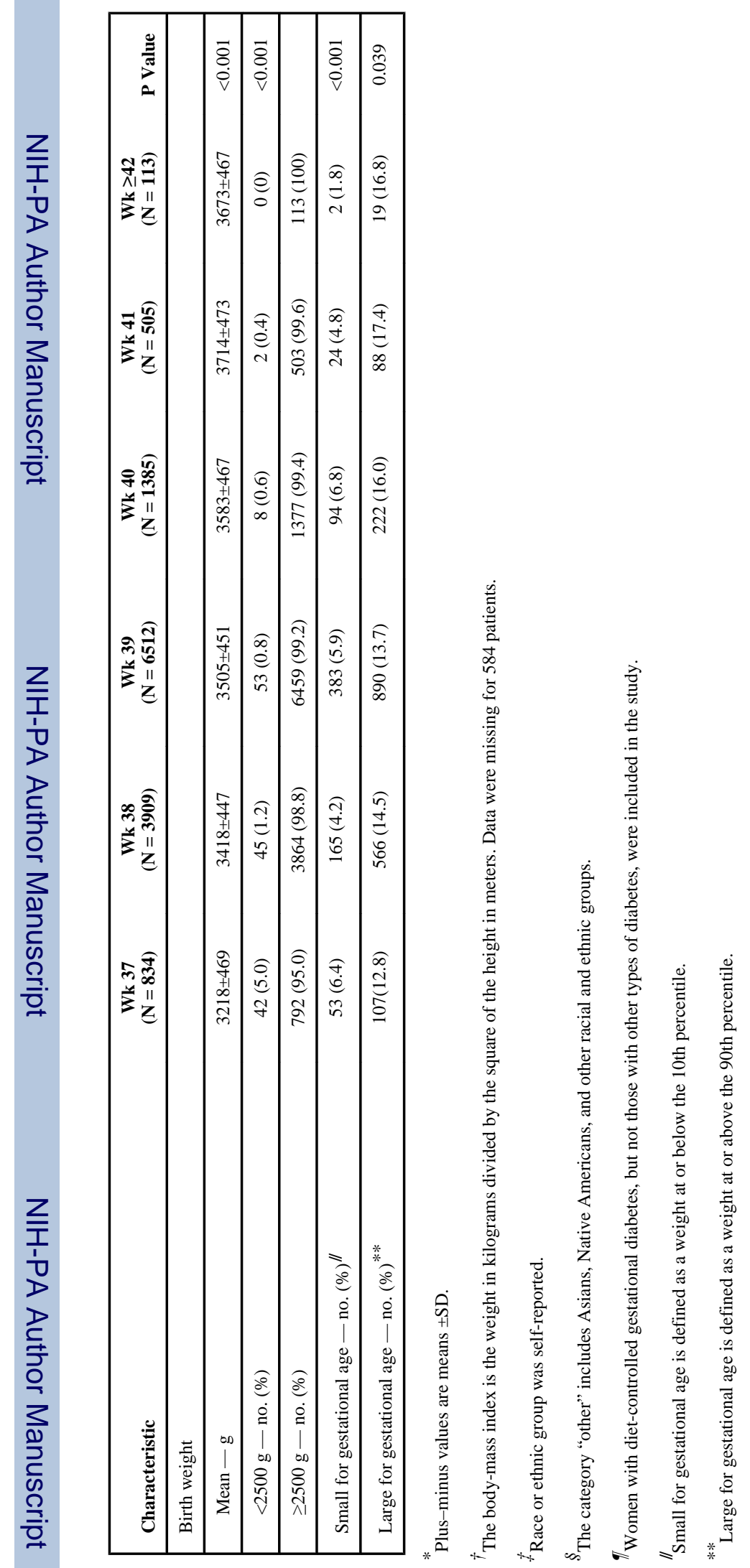

N Engl J Med. Author manuscript; available in PMC 2010 January 26. 


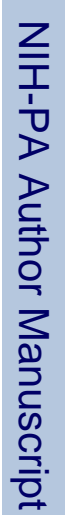

\begin{tabular}{|c|c|c|c|c|c|c|c|c|c|c|c|}
\hline 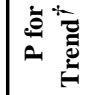 & $\begin{array}{l}\vec{\Xi} \\
\dot{\theta} \\
\dot{v}\end{array}$ & \begin{tabular}{|l|}
$\vec{\delta}$ \\
$\dot{\vec{Q}}$ \\
$\dot{v}$
\end{tabular} & \begin{tabular}{|l|}
$\overrightarrow{0}$ \\
$\dot{0}$ \\
$\dot{v}$
\end{tabular} & \begin{tabular}{|l|}
$\bar{\delta}$ \\
$\dot{0}$ \\
$\dot{v}$
\end{tabular} & $\begin{array}{l}\overline{8} \\
\dot{0} \\
\dot{\nabla}\end{array}$ & $\begin{array}{l}\overline{8} \\
\stackrel{\circ}{\dot{V}}\end{array}$ & 偘 & $\begin{array}{l}\bar{\delta} \\
\dot{v} \\
\dot{v}\end{array}$ & $\begin{array}{l}\bar{\delta} \\
\dot{\nabla} \\
\dot{v}\end{array}$ & $\begin{array}{l}\overrightarrow{8} \\
\dot{\nabla} \\
\dot{v}\end{array}$ & $\begin{array}{l}\bar{\Xi} \\
\dot{\nabla}\end{array}$ \\
\hline 79 & $\begin{array}{l}1 \\
2 \\
2 \\
0\end{array}$ & 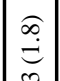 & $\begin{array}{c}\widehat{A} \\
\hat{e} \\
0\end{array}$ & $\begin{array}{c}\stackrel{\sigma}{\infty} \\
\stackrel{\infty}{e}\end{array}$ & 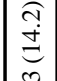 & 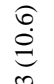 & $\stackrel{\cong}{\Xi}$ & $\underset{\sim}{\stackrel{\infty}{\rightleftarrows}}$ & $\stackrel{m}{=}$ & $\stackrel{\cong}{=}$ & $\stackrel{n}{\stackrel{n}{Z}}$ \\
\hline
\end{tabular}

ż

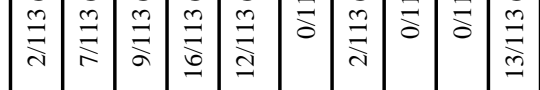

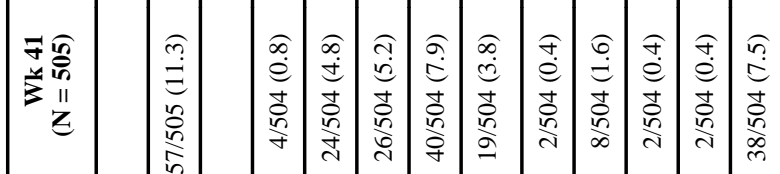

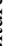

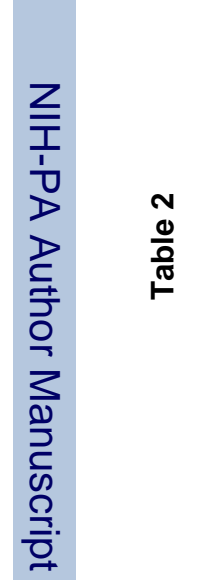

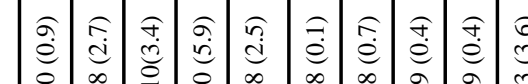

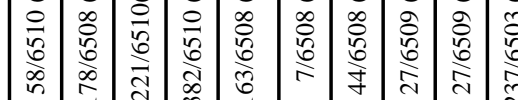

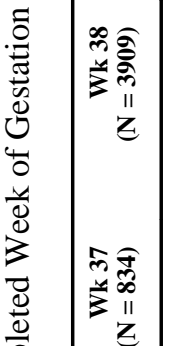

20

造

苛䒕

亏ิ

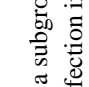

焉

远

:

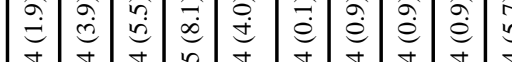

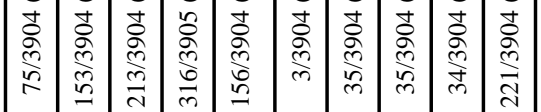

胥

ते

竞

焉

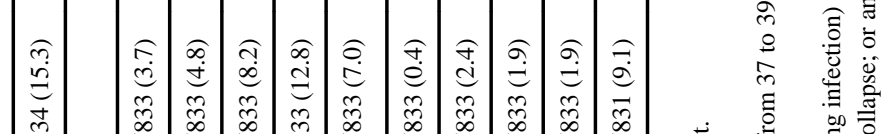

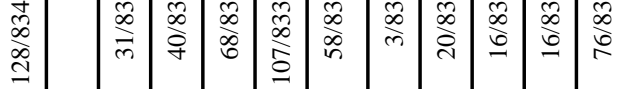

छี

Z

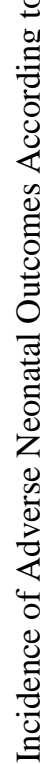

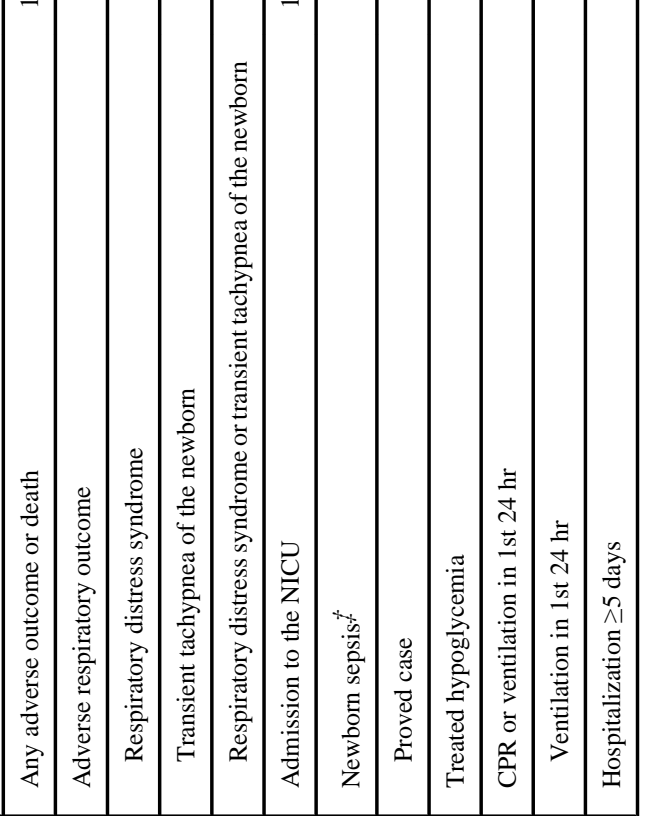

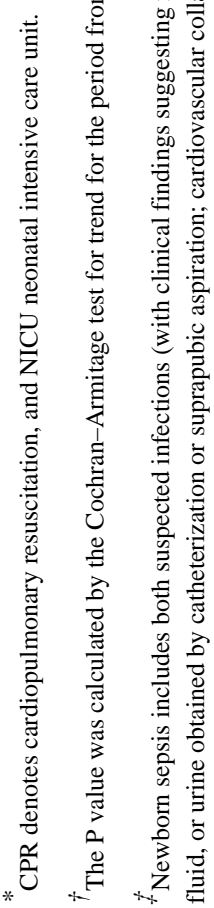

N Engl J Med. Author manuscript; available in PMC 2010 January 26. 

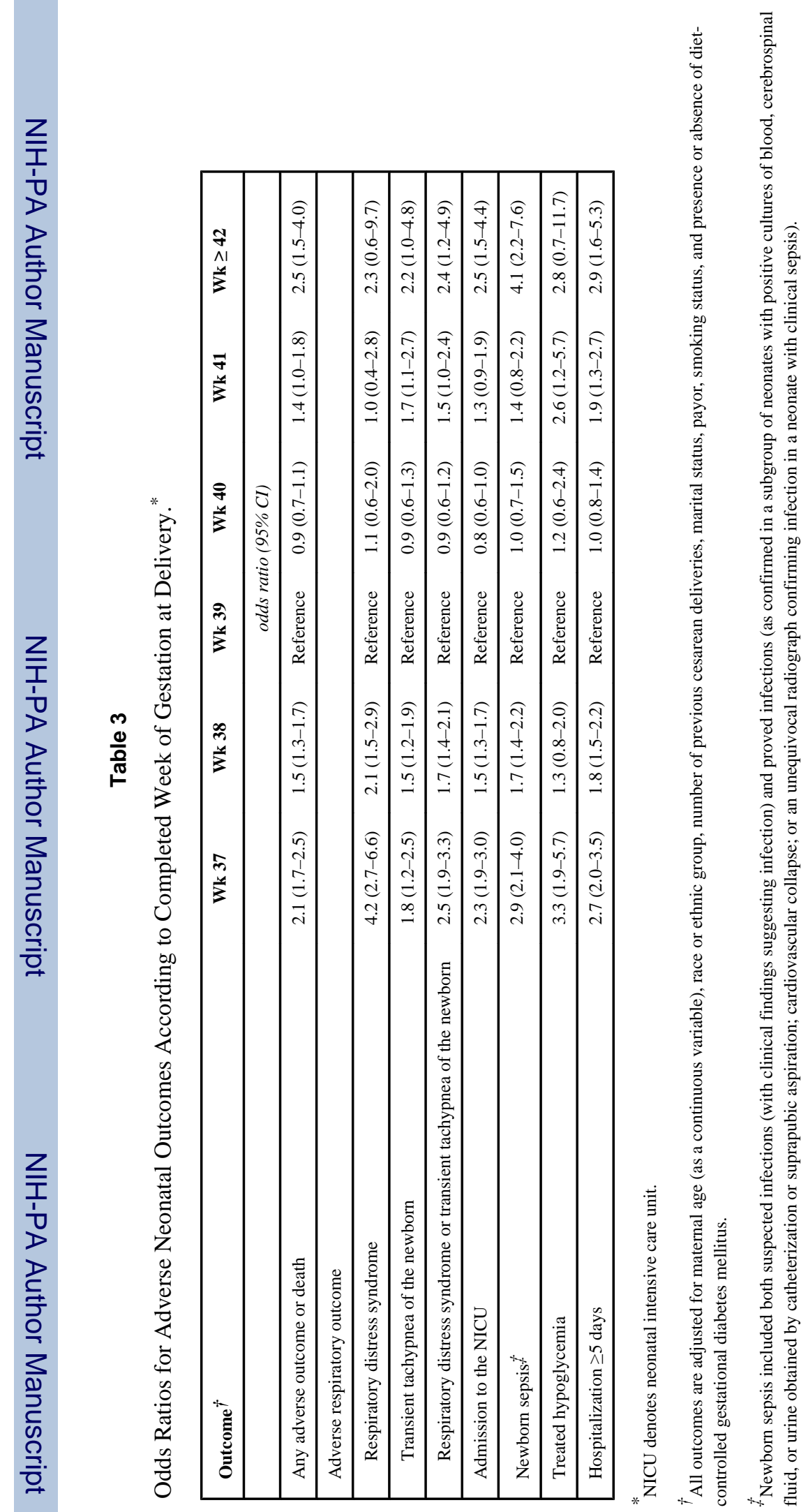

N Engl J Med. Author manuscript; available in PMC 2010 January 26. 